\title{
Renal Cell Carcinoma with Rhabdoid Features: Report of a Rare Case Diagnosed on Endobronchial Ultrasound-Guided Fine Needle Aspiration
}

\author{
Wei Xie M.D., Ph.D. ${ }^{1}$, Bettye Cox M.D. ${ }^{1}$, Nimesh R. Patel M.D. ${ }^{2}$, Marilyn M. Li, M.D. ${ }^{2}$ \\ Rodolfo Laucirica M.D. ${ }^{1,3}$ \\ 1. Department of Pathology \& Immunology, Baylor College of Medicine, Houston, \\ Texas \\ 2. Department of Molecular and Human Genetics, Baylor College of Medicine, Houston, \\ Texas \\ 3. Department of Pathology, Ben Taub General Hospital, Houston, Texas
}

\begin{abstract}
:
Renal cell carcinoma (RCC) with rhabdoid features is a rare subtype of RCC. We describe the case of a 36-year-old man who presented with neck pain, and MRI which showed two infiltrative masses in the vertebral bodies. An abdominal CT demonstrated a heterogeneous mildly enhancing mass in the superior pole of the right kidney with internal necrosis. A chest CT revealed multiple enlarged hilar lymph nodes. EBUSguided FNA was performed. The smears and cell block material showed loose clusters and single neoplastic cells with large vesicular nuclei and prominent nucleoli and abundant eosinophilic cytoplasm with fine vacuoles and granules. The tumor cells were positive for CAM 5.2, P53, EMA (Focally positive), and negative for RCC and CD 10 by IHC and positive for the VHL W117fs mutation by Sanger sequencing. These results were consistent with the diagnosis of RCC with rhabdoid features, which is consistent with surgical diagnosis. To our knowledge, this is the first report of RCC with rhabdoid features diagnosed by endobronchial ultrasound-guided fine needle aspiration (EBUSguided FNA).
\end{abstract}

Key words: Renal cell carcinoma, rhabdoid features, EBUS-guided FNAs

\section{Introduction}

Renal cell carcinoma (RCC) with rhabdoid features is a rare tumor which accounts for 3-5\% of primary RCC (9). Sarcomatoid transformation is most common in clear cell RCC, but it can also be involved in other renal tumors, such as papillary RCC, collecting duct carcinoma and chromophobe RCC (4). Rhabdoid features are seen in RCC with sarcomatoid transformation. However, definite relationship between rhabdoid features and sarcomatoid transformation remains unknown (15). These rhabdoid features are characteristic of a high histologic grade and pathological stage of RCC, and usually associated with aggressive behavior and poor prognosis $(9,27)$. The mean age at presentation is 60-years-old. Clinically, most patients present with an abdominal mass, hematuria or abdominal pain (9). In Leroy's study, 9 of 14 cases of renal cell carcinoma with rhabdoid features were staged pT3, all rhabdoid foci were classified as nuclear grade 4, and the median of survival was eight months (15). 
The rhabdoid components are characterized by sheets of large discohesive epithelioid cells, eccentric nuclei, eosinophilic cytoplasmic inclusions, and prominent nucleoli. Recognizing these rhabdoid features is critical from a clinical standpoint, given their association with higher grade and stage of diseases. These rhabdoid features are not only seen in kidney tumors, but also in primary tumors of other organs and systems including lung, thyroid gland, soft tissue, gastrointestinal system, genitourinary system, and central nervous system $(1,11,13,15,22$, $28)$. It is critical to distinguish RCC with rhabdoid features from other types of cancers with similar cytomorphology. This distinction is important as management and prognostic significance are different. Endobronchial ultrasoundguided fine needle aspiration (EBUSFNA) is an effective method in obtaining diagnostic tissues for the pathologic diagnosis. EBUS-FNA can evaluate organs within the mediastinum or abdominal cavity, as well as small focal lesions. It not only differentiates between malignant and non-malignant lesions, but also between the various tumors from different origins (24). More importantly, EUBS-FNA is an important tool for the diagnosis of primary and metastatic $\operatorname{RCC}(16,20)$. We report a case with atypical presentation of RCC with rhabdoid features, which was diagnosed by EBUS-FNA and confirmed by immunohistochemistry.

\section{Case Report}

A 36-year-old previously healthy male patient presented with neck pain and numbness radiating to the posterior side of his left arm and shoulder, and left fingers. Muscle relaxants or steroids could not relieve the symptoms. MRI performed elsewhere showed a C-spine mass with a fracture. Physical examination showed no abrasions, ecchymosis, laceration, or deformity of spine. Spurling's test was positive reproduced left arm numbness and tingling. The patient was a nonsmoker without significant medical and family history. An abdominal CT demonstrated a $7.2 \times 5.3 \times 4.8 \mathrm{~cm}$ heterogeneous mildly enhancing mass in the superior pole of the right kidney with internal necrosis. Chest CT demonstrated lymphadenopathy of the right hilum and an aortocaval lymph node, which might represent nodal involvement. Contrast enhanced MRI showed two metastatic infiltrative masses in the C6 vertebral body (Figure 1A-C). A destructive soft tissue mass occupying the anterior and posterior T4 vertebral body showed heterogeneous enhancement.

EBUS-guided FNA procedure was performed under monitored anesthesia. Cytology samples were obtained during EBUS-guided FNA using 22-gauge needle. The specimen was expressed on the slides, stained with Diff-Quik, Papanicolaou-stained smears and H\&Estained cellblock preparations were made for evaluation and diagnosis.

The biopsy specimens were attained by ultrasound guided evaluation of right cervical lymph nodes, and fixed in $10 \%$ formalin, embedded in paraffin and stained with hematoxylin-eosin.

\section{Immunohistochemistry}

Immunohistochemical staining was performed with markers as follows: P53, CAM5.2, EMA, RCC and CD 10.

\section{Sanger Sequencing}

DNA extraction: Genomic DNA was extracted from paraffin-embedded tissues from the C6 vertebral lesion 
biopsy using the Maxwell CSC DNA FFPE Kit in combination with the Maxwell CSC Instrument (Promega, Madison, WI). DNA quality and quantity were measured by using Nanodrop (Thermo Fisher Scientific, Wilmington, DE). Primers for all exons flanked the respective intron/exon junctions. Direct sequence analysis of PCR products was performed in both forward and reverse directions using automated fluorescence dideoxy sequencing methods. Reference sequences NM_000551.2 and NT_022517.17 were used for sequence comparison. The nomenclature was based on the convention recommended by the Human Genome Variation Society (http://www.hgvs.org/mutnomen/).

\section{Results:}

5. 1. Cytology and Histology: EBUSguided FNA was performed on the 10R lymph node. The smears and cell block material demonstrated loose clusters and single neoplastic cells having large vesicular nuclei with prominent nucleoli and abundant finely vacuolated and granular esoinophilc cytoplasm (figure 2 A-D, 2 A). Histopathology of the subsequent biopsy of the C6 vertebral lesion had large discohesive tumor cells with eccentric nuclei, eosinophilic cytoplasmic inclusions, and prominent nucleoli (figure $4 \mathrm{~A}, \mathrm{~B}$ ).

5. 2 Immunohistochemistry: The tumor cells in the cell block and vertebral lesion biopsy were positive for vimentin, P53, EMA (focally positive), and Cam5.2 (weak)(figure 3 B-D, 3 C-D), and negative for RCC and CD10.
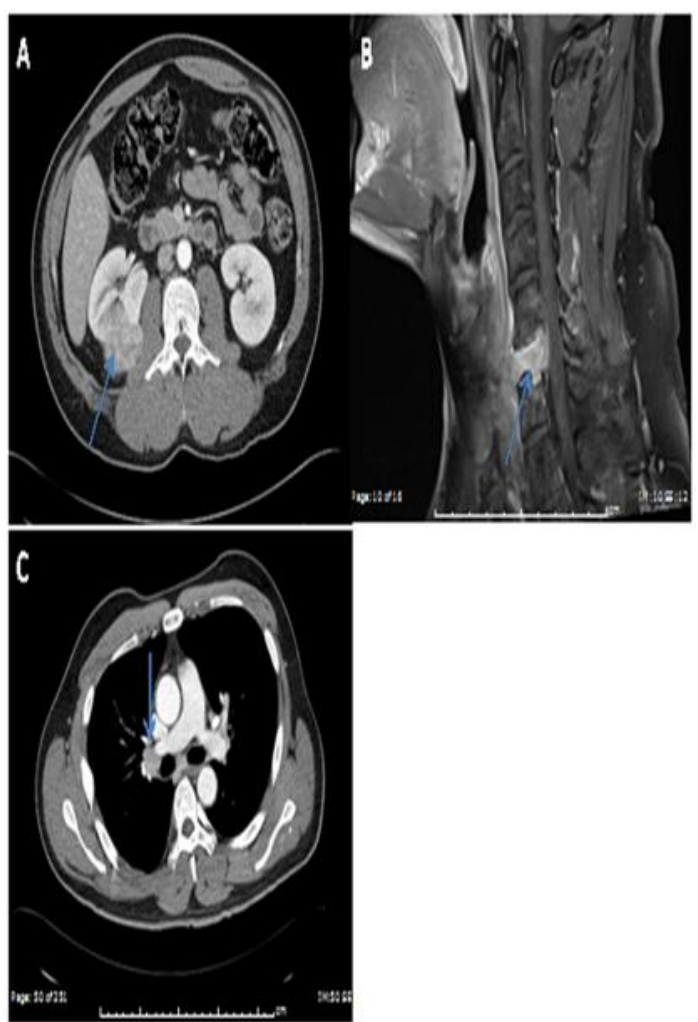

Figure 1: A. Contrast enhanced images in the axial (a), coronal (b), and sagittal (c) planes through a heterogeneous, macrolobulated, and mildly enhancing right renal mass. The areas of decreased attenuation could represent small areas of internal necrosis. No venous involvement was seen on imaging. B. Contrast enhanced MRI with axial (a) and sagittal (b) slices through the C6 soft tissue mass. There is mass effect on the thecal sac at this level due to erosion vertebral body and pedicle. C. Contrastenhanced CT in the axial plane shows an irregular and enlarged right hilar lymph node. This lymph node was ultimately sampled via FNA. 


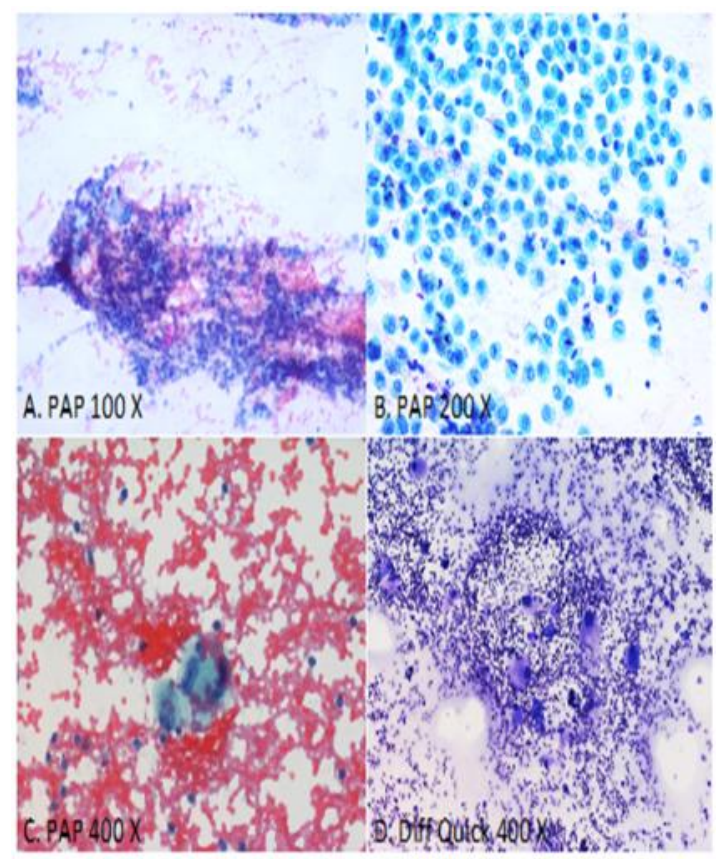

Figure 2: EBUS-FNA of renal cell carcinoma with rhabdoid features shows large tumor cells with eccentric nuclei and abundant cytoplasm. A. Papanicolaou stained (PAP), $100 \times \mathrm{B}$. Papanicolaou stained, $200 \times$. C. Papanicolaou stained, $400 \times$ D. DiffQuick, $400 \times$

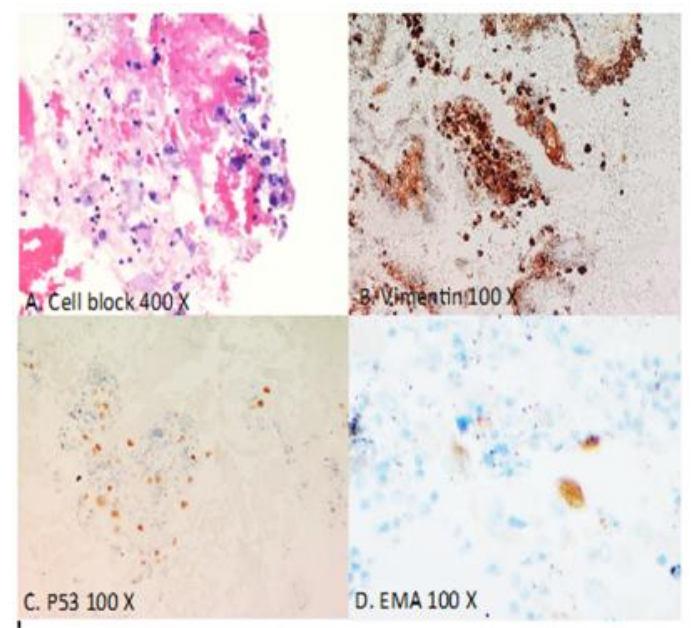

Figure 3: Cell block of renal cell carcinoma with rhabdoid features and immunohistochemical stains. A. H\&E, $400 \times$. B. Vimentin was positive for tumor cells, $100 \times$. C. p53 shows nuclear positivity in tumor cells $100 \times$. D. CD10 was positive for tumor cells, $200 \times$.

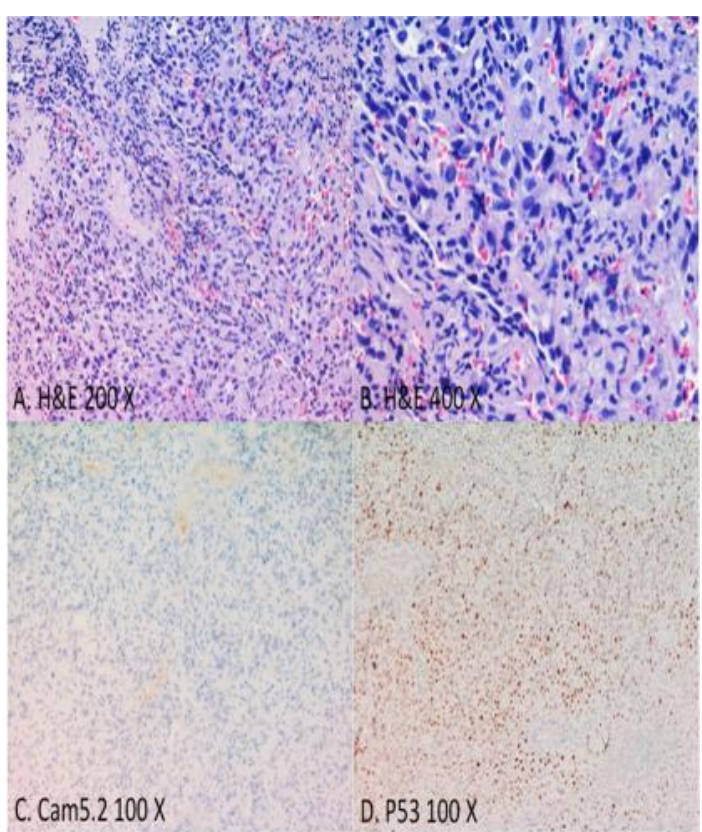

Figure 4: Histopathology of renal cell carcinoma with rhabdoid features show large discohesive tumor cells with eccentric nuclei, eosinophilic cytoplasmic inclusions, and prominent nucleoli. A. H\&E $200 \times$ B. H\&E $400 \times$. C. Cam5.2 was negative for tumor cells, $100 \times$. D. P53 is positive for tumor cells (nuclear), $100 \times$.

5. 3 Sanger Sequencing: The paraffinembeded block of the C6 vertebral lesion biopsy was submitted for VHL gene mutation analysis. The sequence analysis identified a mosaic c.349del (p.W117fs) mutation. This frameshift mutation is predicted to result in a premature translation stop downstream of the deletion (figure 5). 


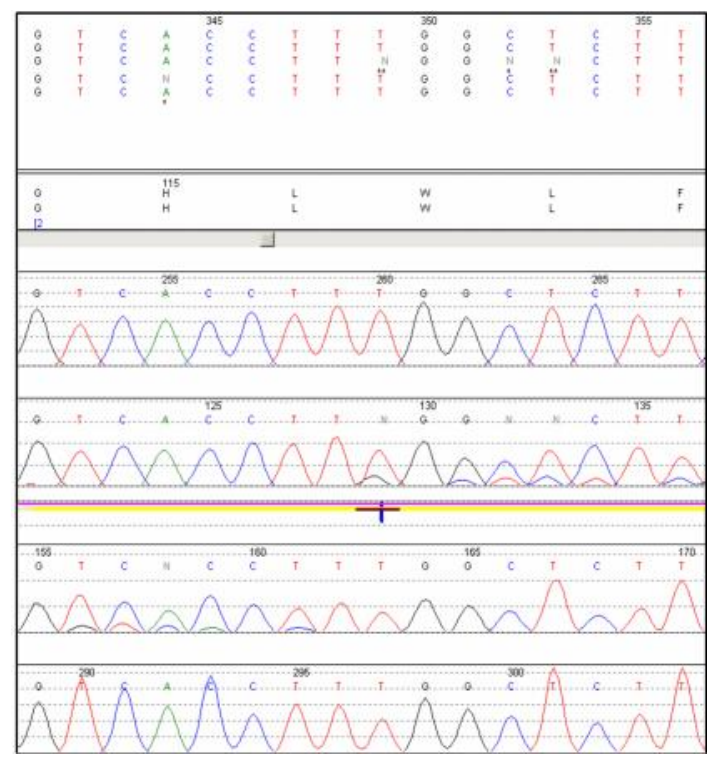

Figure 5: The sequence analysis identified a mosaic c349del (p.W117fs) mutation. This frameshift mutation is predicted to result in a premature translation stop downstream of the deletion (p.W117fs).

\section{Discussion}

FNA is a commonly used approach to rule in or out a metastasis in patients presenting with tumors of unknown primary (20). The most common organs of primary tumors are lung, melanoma and kidney (20), though broader differential diagnosis should be kept in mind. RCC with rhabdoid features is a rare entity. The incidence of RCC with rhabdoid features ranges from $3.1 \%$ to $7.4 \%$ (9). To the best of our knowledge, metastatic RCC with rhabdoid features diagnosed by EBUS-FNA has not been previously reported. Cytomorphology of RCC with rhabdoid features includes discohesive tumor cells with eccentric nuclei, eosinophilic cytoplasmic inclusions, and prominent nucleoli, which are defined features of rhabdoid cells. The differential diagnosis is broad, because neoplasms with rhabdoid features include primary adenocarcinomas from the gastrointestinal system, genitourinary system, respiratory system, central nervous system, and malignant melanoma $(2,3,17,26)$. In addition, some soft tissue neoplasms such as epithelioid sarcomas and synovial sarcoma also have rhabdoid features (19, 25). In this case, the cytological features were highly suggestive of metastasis from the renal neoplasm when combined with imaging studies and clinical history. Recognizing these features is crucial in patient care as it can avoid unnecessary surgical procedures for patients with advanced diseases.

The cytomorphology varies according to different subtype of RCC, and the most common type of RCC is clear cell (conventional) RCC (16). Tumor cells of this type are characterized by irregular nuclear contours, centrally located nuclei and prominent nucleoli with clear or granular cytoplasm. However, tumor cells of this case have rhabdoid features without typical cytoplasmic features of clear cell RCC. Since this patient is young, other subtypes of RCC, such as the recently described Xp11.2 translocation-associated RCC, were also considered. This subtype is commonly seen in the pediatric population and in young adults. The tumor cells can also have eccentrical nuclei, irregular nuclear contour with prominent nucleoli, but the cytoplasm is usually clear or granular, which is similar to clear cell RCC(29).

Immunohistochemistry was also used to establish the diagnosis. We used P53, CAM5.2, EMA, RCC and CD 10. The tumor cells were positive for CAM 5.2, P53, EMA (focally positive), and negative for RCC and CD10 (figure). These results are suggestive of $\mathrm{RCC}$ 
with rhabdoid features, though these immunohistochemical stains are neither sensitive nor specific. More importantly, since the tissue for FNA is limited, the results of stains need to be interpreted with caution. After diagnosis was established by EUS-FNA, subsequent biopsy of the C6 vertebral lesion was obtained, and histopathology showed large discohesive tumor cells with eccentric nuclei, eosinophilic cytoplasmic inclusions, and prominent nucleoli. These histomorphological features were similar to those found in the EUS-FNA specimen. Additionally, the results of immunohistochemical stains showed the same results as those in the FNA specimen.

In addition to immunohistochemistry, sequencing studies are a useful ancillary tool to aid in diagnosis. The von HippelLindau (VHL) gene is a tumor suppressor gene on chromosome $3 \mathrm{p} 25$ discovered in 1993. Inactivation of $V H L$ gene contributes to von Hippel-Lindau tumor syndrome, which is characterized by multiple tumors including pheochromocytoma, clear cell renal cell carcinoma of the kidney, and vascular tumors including benign hemangioblastomas of the cerebellum, spine, brain stem and retina (8). Clear cell RCC is a common cause of death of patients with VHL (8).

The protein product of the $V H L$ gene is a $35 \mathrm{kDa}$ protein, which is part of a complex including elongin $\mathrm{B}$, elongin $\mathrm{C}$, $\mathrm{Cu} 2$ and Rbx1 (VCB-CUL2 complex) (5). The N-terminal beta-sheet domain of VHL binds substrates, and its C-terminal $\alpha$-helical domain interacts with elongin $B$ and elongin $C(5,23)$. Targets of the VCB-CUL2 complex include hypoxiainducible factor 2-alpha (HIF-2 $\alpha$ ), which stimulates other signaling pathways when oxygen levels are changed in the body. In the condition of hypoxia, HIF induces formation of angiogenesis by regulating production of erythropoietin, and vascular endothelial growth factor (VEGF), which is involved in tumorigenesis. More than 370 inherited mutations in the VHL gene have been reported in patients with Von HippleLindau Syndrome, and somatic mutations in the VHL gene are associated with clear cell RCC(6). When the VHL gene is mutated, the VCBCUL2 complex cannot degrade HIF- $2 \alpha$, and thus HIF can accumulate in the body. Consequently, it stimulates angiogenesis in non-hypoxia conditions such as tumorigenesis. On the other hand, VHL also functions in an HIFindependent way and plays a role in other cellular functions, such as secreting extracellular matrix components, regulating nuclear factor kappa B activity and maintaining microtubule stability $(12,14,18,30)$. The tumor in our case showed a mosaic c.349del (p.W117fs) mutation. Interestingly, $35 \%$ to $75 \%$ of clear cell RCC with VHL mutations have been reported according to different studies (6); however, to our knowledge, the presence of $V H L$ gene mutations in cases of RCC with rhabdoid features has been rarely reported (21). Loss of heterozygosity at the $V H L$ locus has been found in $98 \%$ of clear cell RCC cases $(7,10)$. On the contrary, other renal neoplasm such as clear cell papillary renal cancer or translocation carcinomas often lack VHL mutations (7).

The significance of a mutated $V H L$ gene in RCC with rhabdoid features is unknown. However, mutations of the 
VHL gene have been reported to be related to tumor initiation and progression to metastasis in clear cell RCC, and be associated with poor prognosis (7).The patient was transferred to another hospital; the clinical outcome of this patient is unknown. However, a poor prognosis is expected based on pathological findings and the stage 4 disease.

\section{Conclusion:}

To our knowledge, this is the first case report of RCC with rhabdoid features diagnosed by EBUS-guided FNA. RCC with rhabdoid features should be considered in the differential diagnosis of an FNA specimen composed entirely of cells with rhabdoid morphology. Furthermore, it is the one of rare reports of VHL gene mutation in a patient with RCC with rhabdoid features. Mutations in VHL gene can be seen in RCC with rhabdoid features and may represent an adverse prognostic factor for these patients. 


\section{Reference:}

1. Agranovich AL, Ang LC, Griebel RW, Kobrinsky NL, Lowry N, Tchang SP. Malignant rhabdoid tumor of the central nervous system with subarachnoid dissemination. Surg Neurol 37: 410-414, 1992.

2. Biggs PJ, Garen PD, Powers JM, Garvin AJ. Malignant rhabdoid tumor of the central nervous system. Hum Pathol 18: 332-337, 1987.

3. Cavazza A, Colby TV, Tsokos M, Rush W, Travis WD. Lung tumors with a rhabdoid phenotype. Am J Clin Pathol 105: 182-188, 1996.

4. de Peralta-Venturina M, Moch H, Amin M, Tamboli P, Hailemariam S, Mihatsch $\mathrm{M}$, Javidan J, Stricker H, Ro JY, Amin MB. Sarcomatoid differentiation in renal cell carcinoma: a study of 101 cases. Am J Surg Pathol 25: 275-284, 2001.

5. Forman JR, Worth CL, Bickerton GR, Eisen TG, Blundell TL. Structural bioinformatics mutation analysis reveals genotype-phenotype correlations in von Hippel-Lindau disease and suggests molecular mechanisms of tumorigenesis. Proteins 77: 84-96, 2009.

6. Foster K, Prowse A, van den Berg A, Fleming S, Hulsbeek MM, Crossey PA, Richards FM, Cairns P, Affara NA, FergusonSmith MA, et al. Somatic mutations of the von HippelLindau disease tumour suppressor gene in non-familial clear cell renal carcinoma. Hum Mol Genet 3: 2169-2173, 1994.
7. Frew IJ, Moch H. A Clearer View of the Molecular Complexity of Clear Cell Renal Cell Carcinoma. Annu Rev Pathol, 2014.

8. Friedrich CA. Genotypephenotype correlation in von Hippel-Lindau syndrome. Hum Mol Genet 10: 763-767, 2001.

9. Gokden N, Nappi O, Swanson PE, Pfeifer JD, Vollmer RT, Wick MR, Humphrey PA. Renal cell carcinoma with rhabdoid features. Am J Surg Pathol 24: 1329-1338, 2000.

10. Gossage L, Eisen T. Alterations in VHL as potential biomarkers in renal-cell carcinoma. Nat Rev Clin Oncol 7: 277-288, 2010.

11. Harris M, Eyden BP, Joglekar VM. Rhabdoid tumour of the bladder: a histological, ultrastructural and immunohistochemical study. Histopathology 11: 1083-1092, 1987.

12. Hergovich A, Lisztwan J, Barry $\mathrm{R}$, Ballschmieter $\mathrm{P}$, Krek W. Regulation of microtubule stability by the von HippelLindau tumour suppressor protein pVHL. Nat Cell Biol 5: 64-70, 2003.

13. Kapoor A, Tutino R, Kanaroglou A, Hotte SJ. Treatment of adult rhabdoid renal cell carcinoma with sorafenib. Can Urol Assoc J 2: 631-634, 2008.

14. Kurban G, Duplan E, Ramlal N, Hudon V, Sado Y, Ninomiya Y, Pause A. Collagen matrix assembly is driven by the interaction of von Hippel-Lindau tumor suppressor protein with hydroxylated collagen IV alpha 
2. Oncogene 27: 1004-1012, 2008.

15. Leroy X, Zini L, Buob D, Ballereau C, Villers A, Aubert S. Renal cell carcinoma with rhabdoid features: an aggressive neoplasm with overexpression of p53. Arch Pathol Lab Med 131: 102-106, 2007.

16. Lew M, Foo WC, Roh MH. Diagnosis of metastatic renal cell carcinoma on fine-needle aspiration cytology. Arch Pathol Lab Med 138: 1278-1285, 2014.

17. Nishihara K, Katsumoto F, Kurokawa Y, Toyoshima S, Takeda S, Abe R. Anaplastic carcinoma showing rhabdoid features combined with mucinous cystadenocarcinoma of the pancreas. Arch Pathol Lab Med 121: 1104-1107, 1997.

18. Ohh M, Yauch RL, Lonergan KM, Whaley JM, StemmerRachamimov AO, Louis DN, Gavin BJ, Kley N, Kaelin WG, Jr., Iliopoulos $\mathrm{O}$. The von Hippel-Lindau tumor suppressor protein is required for proper assembly of an extracellular fibronectin matrix. Mol Cell 1: 959-968, 1998.

19. Oshiro Y, Shiratsuchi H, Oda Y, Toyoshima S, Tsuneyoshi M. Rhabdoid features in leiomyosarcoma of soft tissue: with special reference to aggressive behavior. Mod Pathol 13: 1211-1218, 2000.

20. Roh MH, Dal Cin P, Silverman SG, Cibas ES. The application of cytogenetics and fluorescence in situ hybridization to fine-needle aspiration in the diagnosis and subclassification of renal neoplasms.
Cytopathology 118: 137-145, 201

21. Shannon B, Stan Wisniewski Z, Bentel J, Cohen RJ. Adult rhabdoid renal cell carcinoma. Arch Pathol Lab Med 126: 15061510, 2002.

22. Shannon B, Wisniewski ZS, Bentel J, Cohen RJ. Adult Rhabdoid Renal Cell Carcinoma. Arch Pathol Lab Med 126: 15061510, 2002.

23. Stebbins CE, Kaelin WG, Jr., Pavletich NP. Structure of the VHL-ElonginC-ElonginB complex: implications for VHL tumor suppressor function. Science 284: 455-461, 1999.

24. Tadic M, Stoos-Veic T, Kusec R. Endoscopic ultrasound guided fine needle aspiration and useful ancillary methods. World J Gastroenterol 20: 14292-14300, 2014.

25. Tsuneyoshi M, Daimaru Y, Hashimoto H, Enjoji M. The existence of rhabdoid cells in specified soft tissue sarcomas. Histopathological, ultrastructural and immunohistochemical evidence. Virchows Arch A Pathol Anat Histopathol 411: 509-514, 1987.

26. Utsunomiya T, Yao T, Masuda $\mathrm{K}$, Tsuneyoshi M. Vimentinpositive adenocarcinomas of the stomach: co-expression of vimentin and cytokeratin. Histopathology 29: 507-516, 1996.

27. Weeks DA, Beckwith JB, Mierau GW, Zuppan CW. Renal neoplasms mimicking rhabdoid tumor of kidney. A report from the National Wilms' Tumor Study Pathology Center. Am J 
Surg Pathol 15: 1042-1054, 1991.

28. Weiss E, Behring B, Behnke J, Christen HJ, Pekrun A, Hess CF. Treatment of primary malignant rhabdoid tumor of the brain: report of three cases and review of the literature. Int $\mathrm{J}$ Radiat Oncol Biol Phys 41: 1013-1019, 1998.

29. Yan BC, Mackinnon AC, AlAhmadie HA. Recent developments in the pathology of renal tumors: morphology and molecular characteristics of select entities. Arch Pathol Lab Med 133: 1026-1032, 2009.

30. Yang H, Minamishima YA, Yan Q, Schlisio S, Ebert BL, Zhang $\mathrm{X}$, Zhang L, Kim WY, Olumi AF, Kaelin WG, Jr. pVHL acts as an adaptor to promote the inhibitory phosphorylation of the NF-kappaB agonist Card9 by CK2. Mol Cell 28: 15-27, 2007. 